\title{
Refractory Osteomedullary Disease
}

National Cancer Institute

\section{Source}

National Cancer Institute. Refractory Osteomedullary Disease. NCI Thesaurus. Code C150287.

A finding indicating that a disease has affected the medullary bone and is resistant to treatment. 